\title{
Intraventricular colistin in Gram-negative ventriculoperitoneal shunt infection in two pediatric patients
}

\author{
Ana Sofia Santos ${ }^{1,3} \cdot$ Amets Iraneta $^{2} \cdot$ Mário Matos $^{2} \cdot$ Maria Joao Brito ${ }^{1}$
}

Received: 13 June 2015 / Accepted: 10 September 2015 /Published online: 22 September 2015

(C) Springer-Verlag Wien 2015

\section{Dear Editor,}

The treatment of post-neurosurgical meningitis, ventriculitis, or central nervous system (CNS) shunt infections is a difficult clinical problem and is associated with a high morbimortality rate [5]. The widespread use of antibiotics led to the emergence of Gram-negative bacteria on these infections [2].

In adults, there are numerous reported methods for the treatment of CNS shunts infections, although no randomized, prospective studies have ever been performed [6]. In pediatric patients, there are only a few case reports in the literature. We report two cases of pediatric neurosurgical patients and the clinical data are summarized in Table 1.

A 15-month-old boy, submitted to ventricular-peritoneal shunt (VPS) valve replacement 1 month before, with Escherichia coli and Klebsiella pneumoniae, both extended spectrum $\beta$-lactamases (ESBL) isolated on cerebrospinal fluid (CSF) cultures. On the eighth day of meropenem, after VPS removal, CSF cultures remained positive; an 11-month-old boy with hydrocephalus secondary to neonatal group B streptococcal meningitis was brought to the hospital 16 days after VPS placement and Acinetobacter baumannii was identified in CSF culture. After 6 days of meropenem and amikacin, CSF cultures remained positive.

Ana Sofia Santos

asfaustino@gmail.com

1 Pediatric Infectious Diseases Unit, Hospital Dona Estefânia, CHLC, Lisbon, Portugal

2 Pediatric Neurosurgery Unit, Hospital Dona Estefânia, CHLC, Lisbon, Portugal

3 Serviço Doenças Infecciosas- CHSJ, Alameda Professor Hernani Monteiro, 4200-319 Porto, Portugal
Since our patients did not improve after adequate intravenous antibiotic therapy, we considered the administration of colistin, an old class of cationic, cyclic polypeptide antibiotic. Colistin CSF penetration after intravenous administration appears to be minimal and, although it increases with meningitis, the concentrations achieved may be inadequate [1]. Therefore we considered intraventricular administration.

There is a dose discrepancy recommended to intraventricular use in the reviewed studies. In children the daily dose range from $2000 \mathrm{IU} / \mathrm{kg}(0.16 \mathrm{mg} / \mathrm{kg})$ up to $125,000 \mathrm{IU}$ $(10 \mathrm{mg}$ ) [4]. For our 15- and 11 month-old patients, we decided to dilute colistin with preservative-free $\mathrm{NaCl} 0.9 \%$ to a concentration of $2 \mathrm{mg} / \mathrm{ml}$ and extrapolated the dose to administer based among all the published cases in children: on the first day, a single dose of $1 \mathrm{mg}, 2 \mathrm{mg}$ on the second day followed by $4 \mathrm{mg}$ continued 10 days in patient 1 and 9 days on patient 2. The direct instillation of colistin was achieved through external ventricular devices after the removal of a greater or equal volume of CSF used for daily cultures and cytochemistry, in a mean speed of $0.5 \mathrm{ml} / \mathrm{min}$. Whenever a higher volume of CSF was removed, normosaline sterile solution was instilled. The catheter was closed for at least $1 \mathrm{~h}$.

The decision to stop should be based on the clinical and microbiological response but we consider that a 10-day period after the first CSF-negative culture is a safe option considering the antimicrobial properties of colistin and the risk for toxicity.

Both patients were submitted to simultaneous intraventricular colistin administration and intravenous therapy with a different antimicrobial class, reported susceptible.

Removal of all components of the infected shunt in combination with appropriate antimicrobial therapy is the most effective treatment for CNS shunt infections. Success rates are lower when the shunt is treated in situ because of the ability of many of these microorganisms to adhere to prostheses and survive antimicrobial therapy [6] through the 
Table 1 MRSA: meticillin-resistant Staphylococcus aureus

\begin{tabular}{|c|c|c|c|c|c|c|c|}
\hline Age (months) & $\begin{array}{l}\text { Underlying } \\
\text { disease(s) }\end{array}$ & Foreign body & $\begin{array}{l}\text { Antimicrobial } \\
\text { identification }\end{array}$ & $\begin{array}{l}\text { Antibiotics administered } \\
\text { concomitantly }\end{array}$ & Colistin MIC & $\begin{array}{l}\text { Duration of } \\
\text { intraventricular } \\
\text { colistin (days) }\end{array}$ & $\begin{array}{l}\text { Days to } \\
\text { sterilize CSF }\end{array}$ \\
\hline 15 & $\begin{array}{l}\text { Hydrocephalus, } \\
\text { MRSA peritonitis/ } \\
\text { meningitis }\end{array}$ & VPS & $\begin{array}{l}\text { Escherichia coli } \\
\text { and Klebsiella } \\
\text { pneumonia, } \\
\text { both ESBL }\end{array}$ & Meropenem & $0.75 \mu \mathrm{l} / \mathrm{ml}$ & 14 & 2 \\
\hline 11 & Hydrocephalus & VPS & $\begin{array}{r}\text { Acinetobacter } \\
\text { baumannii }\end{array}$ & Meropenem, amikacin & $<0.5 \mu \mathrm{l} / \mathrm{ml}$ & 13 & 2 \\
\hline
\end{tabular}

VPS ventriculoperitoneal shunt, ESBL extended spectrum $\beta$-lactamases, $M I C$ minimum inhibitory concentration, $C S F$ cerebrospinal fluid

production of biofilm. None of the strains identified on our patients were tested for their ability to form a biofilm.

The exact time to remove the infected catheter should be discussed with the neurosurgical team and it should be considered after the first negative CSF culture [3]. If, as it happened in our patients, is necessary a drainage catheter because of the hydrocephalus an external drain should be placed until the infection is cleared.

The most significant adverse effect related to intraventricular instillation of colistin is reversible chemical ventriculitis and meningitis. It presents as a bacterial meningitis with sterile CSF cultures [3]. Seizures were noted in both patients and anticonvulsants were prescribed with control of symptoms. These episodes were not related to colistin instillation because they happened before the beginning of the topical administration. They were probably secondary to valve dysfunction.

Successful clinical and bacteriological outcome was achieved in both with follow-up time of 17 and 16 months after hospital discharge.

Direct instillation of colistin in the CNS is safe and suitable for treating nosocomial infections by Gram-negative bacteria especially in patients suffering shunt infections difficult to eradicate and/or those unable to undergo surgery to remove the device [6].

We emphasize the lack of guidelines regarding the ideal management in children and further studies of the appropriate colistin pediatric dosage are still required.

The patients' guardians have consented to the submission of the case report for submission to the journal.
Conflict of interest All authors certify that they have no affiliations with or involvement in any organization or entity with any financial interest (such as honoraria; educational grants; participation in speakers' bureaus; membership, employment, consultancies, stock ownership, or other equity interest; and expert testimony or patent-licensing arrangements), or non-financial interest (such as personal or professional relationships, affiliations, knowledge or beliefs) in the subject matter or materials discussed in this manuscript.

\section{References}

1. Antachopoulos C, Karvanen G, Leone M, Broggi G (2010) Serum and cerebrospinal fluid levels of colistin in pediatric patients. Antimicrob Agent Chemother 54:3985-87

2. Cascio A, Conti A, Sinardi L, Iaria C, Angileri FF, Stassi G, David T, Versaci A, Iaria M, David A (2010) Post-neurosurgical multidrugresistant Acinetobacter baumannii meningitis successfully treated with intrathecal colistin. A new case and a systematic review of the literature. Int J Infect Dis 14:e572-e579

3. Karaiskos I, Galani L, Baziaka F, Giamarellou H (2013) Intraventricular and intrathecal colistin as the last therapeutic resort for the treatment of multidrug-resistant and extensively drugresistance Acinetobacter baumannii ventriculitis and meningitis: a literature review. Int J Antimicrob Agent 41:499-508

4. Markantonis SL, Markou N, Fousteri M, Sakellaridis N, Karatzas S, Alamanos I, Dimopoulou E, Baltopoulos G (2009) Penetration of colistin into cerebrospinal fluid. Antimicrob Agent Chemother 53: 4907-10

5. Michalopoulos A, Falagas M (2011) Colistin: recent data on pharmacodynamics properties and clinical efficacy in critically ill patients. Ann Intensiv Care 1:30

6. Tunkel A, Hartman B, Kaplan S, Kaufman B, Roos K, Scheld M, Whitley R (2004) Practice guidelines for the management of bacterial meningitis. Clin Infect Dis 39:1267-84 